\title{
Transformation of the Structure of the Gross Regional Product in Siberian Regions
}

\author{
Valeriy V. Gamukin \\ Department of Finance, Money Circulation, and Credit \\ Tyumen State University \\ Tyumen, Russia \\ valgam@mail.ru
}

\author{
Olga S. Belomyttseva \\ Department of Finance and Accounting \\ Tomsk State University \\ Tomsk, Russia \\ olbel@f123.ru
}

\author{
Larisa S. Grinkevich \\ Department of Economics \\ Tomsk State University \\ Tomsk, Russia \\ nasty_saturn@mail.ru
}

\begin{abstract}
Stability of the national economy is determined by the capacity of regional economies to adapt to the phenomenon of damping external and internal risk factors. In this paper, the authors consider the following main strategies for developing the structure of regional economies: (1) uniforming of the structure of regional economies; (2) individualization of the structure of regional economies; and (3) integration of regions with different structures of their economies into macroregions, where equalization occurs. For the purpose of selection, we resort to the calculation of Ryabtsev, Szalai indices, and the index of structure using the gross regional product of subjects of the Siberian Federal District for the period of 2005-2014. A universal method for the assessment of convergence of regional economies' structures, which is based on gross regional product, has been developed and proposed for testing on the example of other Russian macroregions.
\end{abstract}

Keywords—-gross regional product; Siberian Federal District.

\section{INTRODUCTION}

One of the important factors for the stability of the national economy in the 21 st century is regional economies' capacity for adapting to the damping of external and internal risks. They are not impeded by the experts' traditional apprehension in case of assessment of weak positive trends, authorities' demonstrative efforts to sustain economic stability ${ }^{1}$, or by ordinary people's pessimism in case of assessment of the economic situation in the country. Since the totality of economies of particular regions, eventually, constitutes the main foundation of the national economy; it is crucial to cognize features of the structure of these regional economies and to reveal the trend of its change in time.

1 "Plan of Priority Actions for Ensuring Sustainable Development of Economic and Social Stability in 2015" (approved by the Decree of the RF Government on January 27, 2015, N 98-r) included 60 activities, whereas "The Action Plan of the Government of the Russian Federation, Aimed at Providing Stable Social and Economic Development of the Russian Federation in 2016" (approved by the Russian Prime Minister on March 1, 2016) already includes 120 activities.
Under conditions of economic destabilization, stability of economic structure makes it possible to reckon upon the following factors: balancing properties of economies, economies' capacity for adaptation to changing conditions, economies' readiness for modification under the influence of external environment, and stability of intra- and interregional economic communication [1]. In addition, a positive impact is produced by a large number and variety of economies, which facilitates an equilibration of the general economic situation in the country. This happens due to disparities in the rates of economic development or recession in various regions. If the structure of economy of particular regions appears to be more vulnerable to destabilizing factors; then, the structure of economy in other regions, on the contrary, can be more adaptive to them and ready to employ the changing conditions for the purpose of ensuring economic growth.

\section{LITERATURE REVIEW}

We assume that the following three independent strategies for developing the structure of regional economies have appeared at present.

1) Transformation of the structure of regional economies into the state of uniformity to ensure that they respond to various external and internal macroeconomic challenges in a similar way. This strategy is efficient for compact countries with equal climate conditions, natural resources reserves, developed transportation networks, etc. Most of the European countries come under these conditions so they almost always endure external shocks. The modern economic design of the Eurozone economy is based on equalization of economic structures of particular countries [2-5]. This strategy enables countries not only to solve special economic tasks but also build upon the forecasted equalization of social, political, and other living conditions of the population. It is assumed that that "similarity" of economic structure will result in "similarity" of employment structure [6-8], which is due to ensure similarity of social structure. This approach leads to equal proportions of the formation and distribution of 
collectivized financial funds and thus to equal access to budget services. Finally, equalization of the structure of economy becomes a solution to many public tasks, which are far beyond economic issues.

2) Individualization of the structure of regional economies. Individualization is created by means of selective development of separate elements. This strategy is viable in case of the extended territory of a country, when balanced development of regional economy is impossible due to the climate factor and availability of natural resources. An illustration of this strategy is the construction of socialist economy in the USSR, when each region was assigned a certain specialization and was obliged to develop within it; other sectors except adjacent ones (i.e. maintaining industries) were neglected. Modern China is currently struggling to overcome the consequences of the implementation of this strategy [9]. It is necessary to take into account the fact that this approach had the right to exist under the set geographical and historical conditions but the period of its factual implementation was strongly dependent of the cementing political realia. In fact, individualization of regional economy structure contradicts the uniformity strategy as related to the development of the structure of regional economies and results in an inverse outcome. In this case, imbalances in the structure of employment are inevitable, which leads to the disbalance of social structure. Consequently, economies are faced with disparity in the formation and distribution of collectivized financial funds. Instead of ensuring equal opportunities for formation of sources of means of budget services provision, authorities resort to withdrawing money funds from some regions and transferring them to others. As a result, industrial specialization of the regional economy structure leads to a variety of public problems. In the event of regimen weakening, the risk of separatism leading to disintegration of the country and to the "parade of sovereignties" in the newly formed states, increases. This happened in the USSR in 1991.

3) Integrated strategy. In this case, regions with various structures of economy are integrated into macroregions, which, in turn, attain a comparable or even analogous structure due to compilation of differentiated economies. These macroregions act as enlarged analogies of European countries. In general, this approach assumes a combination of the positive features of the above-mentioned strategies, including the following:

a) equalization of employment and social structures;

b) development of economic ties within macroregions;

c) equalization of fiscal capacity due to harmonization of economic structure and equalization of the tax potential corresponding to it;

d) unification of regional management methods in all aspects (i.e. from the standardized policy of staff training to the weighed international and inter-confessional policy);

e) mitigation of regional separatism risks (Eventually, macroregions arrive at approximately equal operating conditions, which eliminates doubts about the justice of the principles stipulating relations with the central power).

Different countries deploy various types of strategies. In Russia, the first strategy prevails practically in every federal district and subject. In our view, the basic reasons for this are the narrow specialization of regions, which was inherited from the USSR, and the lack of practical action in the context of implementation of regional economic policy incorporating other strategies.

Developing the hypothesis of existence of a third scenario, we refer to the unique current practice of division of the territory of the country into districts, viz. federal districts, the first of which date back to May 13, 2000 when the Decree of the President of the Russian Federation "On the Plenipotentiary of the President of the Russian Federation in the Federal District" was adopted. In spite of the fact that, historically, formation of districts did not pursue the aim of economic or other integration of regions, which constituted the districts, and implied only representation of the President of the country; the paradigm of a single district and single selfidentification within "their" district established itself in the consciousness of politicians, regional elite, and the population.

Elements of the structure of regional economies developed differently in different regions due to historical reasons. Besides, it is important to emphasize the fact that, in general, federal districts were created regardless of the previously established $^{2}$ mechanism of economic division of the territory into district. Only the Far Eastern Federal District's borders corresponded to the borders the Far Eastern economic region. It became an additional scientific task to determine how strongly regional economies' being in alliance with a new group of regions for many years affected the homogeneity of regional economies.

Existence of federal districts caused formation of a certain coherent economic region. Apparently, this region developed under the influence of such centripetal forces as political uniformity, consolidation of information space, implementation of joint social projects, organization and realization of district economic events, exhibitions, tenders, educational, investing programs, etc. In our view, in addition to the overall dynamic development of the economy of all the districts, equalization of the structure of economy of an entering subject and its convergence to the district's indicators in general can be considered as a result of the abovementioned efforts.

For the purpose of revealing harmonization ${ }^{3}$ of the structure of regional economies, we conducted a comparative analysis of regional economies using the indicator "gross regional product" (GRP). Despite the significant

Regarding the Siberian Federal District, 12 subjects constituting it traditionally belong to different economic regions. Altai Republic, Altai Kray, Kemerovo Oblast, Novosibirsk Oblast, Omsk Oblast, and Tomsk Oblast belong to West Siberia; other subjects, to East Siberia.

${ }^{3}$ It is not reasonable to speak of complete harmony. It is difficult to assume that in a short historical period "innerly integrated" district forces could or in the nearest future will be able to yield this result. The main impediment is uneven distribution of mineral resources and varied environmental conditions, the availability of which exerts the strongest impact on the regional economic structure. Therefore, by harmonization we mean only activity towards a certain balanced structure of economy. As a model for comparison, we find it possible to deploy the structure of economy of the district in general; and as a target function, approximation to this structure. 
methodological problems concerned with the calculation ${ }^{4}$, it is the only concise and capacious indicator that enables us to illustrate the structure regional economies.

\section{DATA ANALYSIS AND ESTIMATION METHODOLOGY}

According to the Russian practice, the GRP structure is built upon the information basis of the All-Russia Classifier of Types of Economic Activity (OKVED). The current classification ${ }^{5}$ includes the following sections: A "Agricultural industry, hunting, and forestry"; B "Fishery and fish breeding"; C "Mineral extraction"; D "Processing industries"; $\mathrm{E}$ "Production and distribution of electric power, gas, and water"; F "Construction"; G "Wholesale and retail trade; repair of trucking facilities, motorcycles, household products, and objects of private use"; $\mathrm{H}$ "Hotels and restaurants"; I "Transport and communication"; J "Financial activity"; K "Real estate transactions, lease and provision of services"; L "Public administration and ensuring military safety; obligatory social security"; M "Education"; N "Health care and provision of social services"; O "Provision of other municipal, social and personal services".

The value of the economy of the Siberian Federal District is exceptionally high and this premise is not likely to be questioned in the nearest future. The economy of the district is distinguished not only by the high rate of contribution to the total amount of GRP of the country but also by the high rate of its growth in absolute terms. In the analyzed period of 20052014, the GRP of the district increased from 1.9 trillion rubles to 6.1 trillion rubles based on current prices. Moreover, from 2008 and onwards, the relative share of the district's GRP remained unvaried and equal to $11-10 \%$ of the overall regional GRP. The cause of this dynamics lies in the diversification of the district's economic structure, which underwent substantial changes during the analyzed period (Tab. 1,2).

Taking the vector of change into account, we distinguish three groups of types of activity. The first group comprises OKVED sections, the share of which remained relatively unchanged (fluctuation amounted to $\pm 15 \%$ from the value of 2005). In particular, the share of the OKVED section E "Production and distribution of electric power, gas, and water" shrank by $10.6 \%$. The share of G "Wholesale and retail trade; repair of trucking facilities, motorcycles, household products, and objects of private use" shrank only by $5.6 \%$. Section $\mathrm{H}$ "Hotels and restaurants" increased by $12.5 \%$; section M "Education", by $10.3 \%$.

\footnotetext{
${ }^{4}$ Openness of regional economy impedes setting clear boundaries for added value creation within this territory and high reliability estimation of its size. Availability and features of accounting hinder estimation of production and production costs of production units, being part of such corporations. Therefore, assessment of added value - approved by statistic bodies - with regard to corporations, operating on the basis of integrated vertical and horizontal schemes, is of relative nature, which leads to overstatement of the amount of added value produced in regions where head companies are located and to understatement of added value in the regions of divisions.

${ }^{5}$ This classification was enacted on January 1,2003 and was in-action till late 2016. The structure and methods of identifying components of GRP did not undergo essential changes in the period of analysis (2005-2014), which enabled us to perform an accurate and correct analysis without any adjustments.
}

The second group unites types of activities that demonstrated a more than $15 \%$ decrease in share. These are sections A "Agricultural industry, hunting, and forestry" ($19.2 \%)$, D "Processing industries" (-28.3\%), I "Transport and communication" (-15.9\%), J "Financial activity" (-33.3\%).

TABLE I. StRUCture of THE Gross Regional Product OF THE SIBERIAN FEDERAL DISTRICT (PART 1)

\begin{tabular}{|l|l|l|l|l|l|l|l|}
\hline \multirow{2}{*}{ Year } & \multicolumn{7}{|c|}{ OKVED Sections (\%) } \\
\cline { 2 - 8 } & $\boldsymbol{A}$ & $\boldsymbol{B}$ & $\boldsymbol{C}$ & $\boldsymbol{D}$ & $\boldsymbol{E}$ & $\boldsymbol{F}$ & $\boldsymbol{G}$ \\
\hline 2005 & 7.3 & 0.0 & 9.4 & 27.9 & 4.7 & 4.7 & 12.4 \\
\hline 2006 & 6.9 & 0.0 & 7.5 & 29.3 & 4.3 & 5.3 & 12.3 \\
\hline 2007 & 6.5 & 0.0 & 7.7 & 26.8 & 3.9 & 6.1 & 13.3 \\
\hline 2008 & 6.9 & 0.0 & 9.5 & 22.7 & 4.1 & 6.3 & 13.3 \\
\hline 2009 & 7.4 & 0.0 & 8.5 & 21.2 & 5.0 & 5.6 & 12.4 \\
\hline 2010 & 6.3 & 0.0 & 13.6 & 21.8 & 4.7 & 5.9 & 12.0 \\
\hline 2011 & 6.1 & 0.0 & 14.7 & 20.9 & 4.4 & 6.3 & 12.0 \\
\hline 2012 & 5.2 & 0.0 & 13.1 & 19.4 & 4.1 & 6.7 & 12.1 \\
\hline 2013 & 5.8 & 0.0 & 12.6 & 19.0 & 4.2 & 5.9 & 11.9 \\
\hline 2014 & 5.9 & 0.0 & 12.6 & 20.0 & 4.2 & 6.1 & 11.7 \\
\hline
\end{tabular}

TABLE II. Structure of THE Gross RegionAl Product of THE SIBERIAN FEDERAL DISTRICT (PART 2)

\begin{tabular}{|l|c|c|c|c|c|c|c|c|}
\hline \multirow{2}{*}{ Year } & \multicolumn{7}{|c|}{ OKVED Sections (\%) } \\
\cline { 2 - 9 } & $\boldsymbol{H}$ & $\boldsymbol{I}$ & $\boldsymbol{J}$ & $\boldsymbol{K}$ & $\boldsymbol{L}$ & $\boldsymbol{M}$ & $\boldsymbol{N}$ & $\boldsymbol{O}$ \\
\hline 2005 & 0.8 & 13.2 & 0.3 & 6.3 & 3.6 & 3.9 & 4.3 & 1.2 \\
\hline 2006 & 0.8 & 12.3 & 0.2 & 6.5 & 5.3 & 3.7 & 4.4 & 1.2 \\
\hline 2007 & 0.9 & 12.6 & 0.2 & 7.3 & 5.7 & 3.7 & 4.1 & 1.2 \\
\hline 2008 & 1.0 & 12.5 & 0.2 & 7.6 & 6.3 & 3.9 & 4.5 & 1.2 \\
\hline 2009 & 0.8 & 12.8 & 0.4 & 7.9 & 7.3 & 4.5 & 5.0 & 1.2 \\
\hline 2010 & 0.7 & 11.9 & 0.4 & 7.9 & 6.0 & 3.6 & 4.2 & 1.0 \\
\hline 2011 & 0.8 & 11.1 & 0.4 & 8.5 & 5.9 & 3.6 & 4.3 & 1.0 \\
\hline 2012 & 0.9 & 12.1 & 0.4 & 9.3 & 6.8 & 4.0 & 4.7 & 1.2 \\
\hline 2013 & 0.9 & 11.2 & 0.3 & 10.2 & 7.1 & 4.4 & 5.1 & 1.4 \\
\hline 2014 & 0.9 & 11.1 & 0.2 & 9.9 & 6.7 & 4.3 & 5.0 & 1.4 \\
\hline
\end{tabular}

Statistics Service. Retrieved June 16, 2016, from http//www_gks.ru/free_doc/new_site/vvp/tab-vrp2 ht

The third group of types of activity consists of sections, the share of which expanded by more than by $15 \%$. These are sections C "Mineral extraction" (+34.0\%), F "Construction" $(+29.8 \%), \mathrm{K}$ "Real estate transactions, lease and provision of services" (+57.1\%), L "Public administration and ensuring military safety; obligatory social security" (+86.1\%), N "Health care and provision of social services" $(+16.3 \%)$, and $\mathrm{O}$ "Provision of other municipal, social and personal services" $(+16.7 \%)$.

Activity type B "Fishery and fish breeding" should be considered separately. Its share in the GRP was extremely insignificant and was not included in calculations for the entire analyzed period. Consequently, assessment of this share was not deemed possible; however, this type of activity was taken into account for further calculations. A tendency towards steady reduction of the dominating share of section D "Processing industries" as well as expansion of the share of section C "Mineral extraction" was registered in the analyzed period. Simultaneously, a tendency towards an increase in the share of sections $\mathrm{L}, \mathrm{M}, \mathrm{N}, \mathrm{O}$, belonging to the supporting and social component of economic activity was observed.

Stability of the general state of the district's economy compared to other macroregions enabled us to study the structure and change dynamics within the constituents 
generating the district's GRP. The distinguishing feature of the district under study is its high regional differentiation of specialization, due to which the change of the GRP structure according to types of activity impacted the change of shares of certain subjects. Concurrently, high capacity of regional economies for diversification was revealed. In fact, under the influence of those contra-directional forces, a change in the share of subjects' participation occurred. Subjects, mainly, expanded their share (8 against 4). However, Altai Kray, Zabaykalsky Kray, and Krasnoyarsky Kray demonstrated stagnation in the relative rates of the GRP build-up.

TABLE III. STRUCTURE OF THE GRP OF THE SIBERIAN FEDERAL DISTRICT'S SUBJECTS ${ }^{6}$ IN 2014 (PART 1)'

\begin{tabular}{|l|l|l|l|l|l|l|l|}
\hline \multirow{2}{*}{ Subject } & \multicolumn{7}{|c|}{ OKVED Sections (\%) } \\
\cline { 2 - 8 } & $\boldsymbol{A}$ & \multicolumn{1}{|c}{$\boldsymbol{B}$} & $\boldsymbol{C}$ & \multicolumn{1}{c|}{$\boldsymbol{D}$} & $\boldsymbol{E}$ & $\boldsymbol{F}$ & $\boldsymbol{G}$ \\
\hline R & 5.9 & 0 & 12.6 & 20.0 & 4.2 & 6.1 & 11.7 \\
\hline AR & 16.3 & 0 & 0.9 & 2.8 & 3.8 & 16.1 & 12.1 \\
\hline RB & 5.9 & 0 & 3.5 & 17.4 & 5.0 & 5.2 & 12.4 \\
\hline RT & 6.3 & 0 & 6.5 & 1.2 & 2.9 & 10.8 & 9.7 \\
\hline RKh & 4.9 & 0 & 10.9 & 12.5 & 9.6 & 6.8 & 15.1 \\
\hline AK & 14.5 & 0 & 0.7 & 18.2 & 3.7 & 6.5 & 16.6 \\
\hline ZK & 5.7 & 0 & 7.7 & 3.6 & 4.8 & 3.7 & 13.9 \\
\hline KO & 3.8 & 0 & 16.9 & 30.7 & 4.1 & 6.9 & 8.3 \\
\hline IO & 5.8 & 0 & 19.9 & 12.8 & 5.6 & 6.8 & 9.6 \\
\hline KO & 4.1 & 0 & 21.6 & 19.0 & 4.8 & 5.3 & 9.5 \\
\hline NO & 5.1 & 0 & 1.8 & 12.4 & 3.1 & 5.5 & 17.4 \\
\hline OO & 8.7 & 0 & 0.6 & 37.9 & 2.5 & 4.4 & 13.2 \\
\hline TO & 4.1 & 0 & 28.5 & 9.9 & 3.6 & 6.4 & 10.0 \\
\hline
\end{tabular}

TABLE IV. STRUCTURE OF THE GRP OF THE SIBERIAN FEDERAL DISTRICT's SUBJECTS IN 2014 (PART 2)

\begin{tabular}{|l|l|l|l|l|l|l|l|l|}
\hline \multirow{2}{*}{ Subject } & \multicolumn{7}{|c|}{ OKVED Sections (\%) } \\
\cline { 2 - 10 } & $\boldsymbol{H}$ & $\boldsymbol{I}$ & $\boldsymbol{J}$ & $\boldsymbol{K}$ & $\boldsymbol{L}$ & $\boldsymbol{M}$ & $\boldsymbol{N}$ & $\boldsymbol{O}$ \\
\hline R & 0.9 & 11.1 & 0.2 & 9.9 & 6.7 & 4.3 & 5.0 & 1.4 \\
\hline AR & 1.5 & 3.3 & 0.4 & 7.0 & 17.0 & 9.9 & 7.0 & 1.9 \\
\hline RB & 2.2 & 15.9 & 0.3 & 5.7 & 11.0 & 6.6 & 7.0 & 1.9 \\
\hline RT & 0.8 & 5.9 & 0.2 & 4.8 & 23.6 & 12.3 & 12.7 & 2.3 \\
\hline RKh & 1.2 & 9.1 & 0.2 & 10.2 & 8.2 & 4.1 & 5.7 & 1.5 \\
\hline AK & 0.9 & 7.1 & 0.2 & 11.6 & 7.7 & 4.8 & 5.8 & 1.7 \\
\hline ZK & 0.8 & 23 & 0.2 & 6.9 & 13.4 & 6.9 & 8.0 & 1.4 \\
\hline KO & 0.7 & 7.6 & 0.2 & 6.7 & 5.3 & 3.3 & 4.1 & 1.4 \\
\hline IO & 0.7 & 15.8 & 0.2 & 6.5 & 6.5 & 4.0 & 4.7 & 1.1 \\
\hline KO & 1.0 & 8.7 & 0.2 & 8.7 & 6.3 & 4.0 & 5.5 & 1.3 \\
\hline NO & 0.9 & 15.8 & 0.3 & 20.6 & 6.1 & 4.7 & 4.9 & 1.4 \\
\hline OO & 0.9 & 7.8 & 0.2 & 8.7 & 5.5 & 3.9 & 4.4 & 1.3 \\
\hline TO & 1.0 & 9.5 & 0.2 & \multicolumn{7}{|c|}{10.9} & \multicolumn{2}{|c|}{5.8} & 4.7 & 4.2 & 1.2 \\
\hline
\end{tabular}

Service. Retrieved June 16, 2016, from http://www.gks.ru/free_doc/new_site/vvp/tab-vrp2.htm

This impedes identification of the drift tendency towards more balanced participation of the Siberian Federal District's subjects in the generation of the GRP total amount. Moreover, it is difficult to predict a certain degree of equality of efforts to generate GRP for the district in the distant future even if special methods are applied [10, 11]. Various tendencies towards the change of shares, demonstrating a significant variety of vectors of stagnation, decline or development, are

\footnotetext{
${ }^{6}$ The names of subjects are contracted as follows: AR (Altai Republic), RB (the Republic of Buryatia), RT (the Republic of Tyva), RKh (the Republic of Khakassia), AK (Altai Kray), ZK (Zabaykalsky Kray), KO (Krasnoyarsk Oblast), IO (Irkutsk Oblast), KO (Kemerovo Oblast), NO (Novosibirsk Oblast), OO (Omsk Oblast), TO (Tomsk Oblast), R (Siberian Federal District).
}

detected within each subject. Tab. 3, 4 represent GRP shares according to types of activity in 2014 .

\section{EMPIRICAL RESULTS}

For the purpose of our study, we assessed the identity of rows of indicators according to variation parameters with using indices of square roots, viz. Ryabtsev index and Szalai index [12]. Employment of these indices was expedient because the indices are characterized by relative simplicity of calculation and informational value of obtained results. A rating scale for the evaluation of the degree of importance of structures' distinctions was proposed and implemented for the purposes of calculation of Ryabtsev index, which enabled us not only to obtain formal mathematical results but also to perform evaluation of the degree of identity of the measure of structural distinctions of data rows. Since the calculated values fell into the range from 0.15 to 0.5 , we presented our evaluation scale, where the range from 0.151 to 0.300 implied the essential degree of distinction; the range from 0.301 to 0.500 stood for the significant degree of distinction.

In our study we used the following format of Ryabtsev index (1):

$$
I_{R}=\sqrt{\frac{\sum\left(d_{k s}-d_{k d}\right)^{2}}{\sum\left(d_{k s}+d_{k d}\right)^{2}}}
$$

Where: $d_{k s}$ stands for the indicator of $k$ OKVED section of a subject; $d_{k d}$ is the indicator of $k$ OKVED section of the district.

The results of our calculations are presented in Tab. 5, 6 .

TABLE V. CHANGE OF RYABTSEV INDEX IN SUBJECTS OF THE SIBERIAN FEDERAL DISTRICT (PART 1)

\begin{tabular}{|l|l|l|l|l|l|l|}
\hline \multirow{2}{*}{ Year } & \multicolumn{7}{|c|}{ Subjects } \\
\cline { 2 - 7 } & $\boldsymbol{A R}$ & $\boldsymbol{R B}$ & $\boldsymbol{R}$ & $\boldsymbol{R} \boldsymbol{h}$ & $\boldsymbol{A K}$ & $\boldsymbol{Z} \boldsymbol{K}$ \\
\hline 2005 & 0.51 & 0.35 & 0.49 & 0.17 & 0.27 & 0.43 \\
\hline 2006 & 0.54 & 0.36 & 0.50 & 0.18 & 0.26 & 0.45 \\
\hline 2007 & 0.52 & 0.35 & 0.48 & 0.16 & 0.27 & 0.42 \\
\hline 2008 & 0.47 & 0.31 & 0.47 & 0.21 & 0.24 & 0.36 \\
\hline 2009 & 0.45 & 0.24 & 0.45 & 0.24 & 0.24 & 0.34 \\
\hline 2010 & 0.52 & 0.25 & 0.45 & 0.14 & 0.30 & 0.33 \\
\hline 2011 & 0.53 & 0.22 & 0.47 & 0.19 & 0.27 & 0.33 \\
\hline 2012 & 0.50 & 0.22 & 0.45 & 0.16 & 0.25 & 0.29 \\
\hline 2013 & 0.47 & 0.20 & 0.47 & 0.15 & 0.26 & 0.31 \\
\hline 2014 & 0.48 & 0.20 & 0.48 & 0.16 & 0.25 & 0.35 \\
\hline
\end{tabular}

TABLE VI. CHANGE OF RYABTSEV INDEX IN SUBJECTS OF THE SiBERIAN FEDERAL DISTRICT (PART 2)

\begin{tabular}{|l|l|l|l|l|l|l|}
\hline \multirow{2}{*}{ Year } & \multicolumn{7}{|c|}{ Subjects } \\
\cline { 2 - 7 } & $\boldsymbol{K O}$ & $\boldsymbol{I O}$ & $\boldsymbol{K O}$ & $\boldsymbol{N O}$ & $\boldsymbol{O O}$ & $\boldsymbol{T O}$ \\
\hline 2005 & 0.24 & 0.13 & 0.30 & 0.21 & 0.26 & 0.39 \\
\hline 2006 & 0.27 & 0.09 & 0.25 & 0.24 & 0.18 & 0.33 \\
\hline 2007 & 0.29 & 0.19 & 0.26 & 0.24 & 0.18 & 0.30 \\
\hline 2008 & 0.22 & 0.16 & 0.29 & 0.20 & 0.25 & 0.31 \\
\hline 2009 & 0.21 & 0.16 & 0.28 & 0.17 & 0.24 & 0.26 \\
\hline 2010 & 0.20 & 0.20 & 0.28 & 0.24 & 0.26 & 0.21 \\
\hline 2011 & 0.20 & 0.16 & 0.30 & 0.27 & 0.30 & 0.27 \\
\hline 2012 & 0.17 & 0.14 & 0.22 & 0.25 & 0.31 & 0.30 \\
\hline 2013 & 0.17 & 0.14 & 0.17 & 0.26 & 0.30 & 0.28 \\
\hline 2014 & 0.19 & 0.18 & 0.15 & 0.28 & 0.30 & 0.28 \\
\hline
\end{tabular}


The structure of the economy of the Republic of Khakassia, Kemerovo Oblast, Irkutsk Oblast, and Krasnoyarsk Oblast appeared to be most similar to the structure of the Siberian Federal District economy. The most dissimilar structure was that of the economy of the Republics of Altai, Tyva, Zabaykalsky Kray, Novosibirsk Oblast, Omsk Oblast, and Tomsk Oblast.

It is important to emphasize a tendency towards similarization of the structure of economy of some subjects. The value of the index decreased in most of the subjects except Irkutsk Oblast, Novosibirsk Oblast, and Omsk Oblast in the studied period. It significantly decreased in the Republic of Buryatia and Kemerovo Oblast. In other subjects, the decline was not considerable but stable.

In general, similar results were obtained when we used Szalai index. Despite the fact that the calculation algorithm was different, the interpretation of the index was analogous to the interpretation of Ryabtsev index, viz. the lower the obtained value was, the lower the degree of distinction between compared rows was. In our case, (2) was used.

$$
I_{S}=\sqrt{\frac{\sum \frac{\left(d_{k s}-d_{k d}\right)^{2}}{\left(d_{k s}+d_{k d}\right)^{2}}}{n}}
$$

Where: $d_{k s}$ is the indicator of $k$ OKVED section of a subject; $d_{k d}$ is the indicator of $k$ OKVED section of the district; $n$ means the number of OKVED sections included in the calculations.

During the analyzed period, the structures of economies of all the subjects were affected by centripetal factors, which contributed to the approximation to the average structure within the Siberian Federal District

The revealed weak tendencies of convergence does not allow complete evaluation of the possibility of intensification or weakening of the homogeneity of the economic structure of subjects of the Russian Federation in case of implementation of the integrated strategy for regional development. The use of Ryabtsev index and Szalai index assumes mandatory involvement of the compared row of indicators. Besides, both the indices do not demonstrate a sufficient degree of sensitivity to the change of indicators' values.

For the purpose of indentifying properties of the structure of a particular regional economy, other instruments are traditionally deployed. The simplest of these instruments is calculation of the sum of squared deviations from the mean. The simplicity of the instrument ensures availability of the obtained results for a wide range of interested people. Simultaneously, the above-mentioned advantage of both the indices is retained, that is to say by means of using the power, the sign of the obtained difference is inverted.

Parallel to the search for simpler tools, it is required to increase their sensitivity. With this in mind, instead of singlelevel calculation, we suggest using an algorithm of two-level calculation of the sum of squared deviations of a share of OKVED sections from their average value per subject.
At the first stage, a sum of squared deviations of values from their arithmetic mean value (3) is calculated. This operation is not to deal with the whole sum-total of values involved; on the contrary, with consecutive exclusion of an indicator of each share in a row.

$$
I_{k}=\sum\left(d_{n}-\overline{d_{n}}\right)^{2}
$$

Where: $d_{n}$ stands for the indicator $\mathrm{n} \neq \mathrm{k}$ of OKVED sections; $\overline{d_{n}}$ is the mean indicator for all the sections $n \neq k$.

Since in our case, a row consists of shares constituting the whole $(100 \%)$, consecutive exclusion appears to be correct. This yields a new range of $I_{k}$, values characterizing the degree of influence of $k$ OKVED section on the overall GRP structure. The suggested modification of this calculation enables us to determine and show the degree of influence of particular OKVED sections on the general revenue structure.

We performed our calculations for all time periods but presented only data for 2014 (Tab. 7, 8, 9, 10) due to the paper length constraints.

TABLE VII. VALUES OF $I_{K}$ FOR SUBJECTS BY OKVED SECTIONS IN 2014 (PART 1)

\begin{tabular}{|l|l|l|l|l|}
\hline \multirow{2}{*}{ Subjects } & \multicolumn{4}{|c|}{ OKVED Sections A-D } \\
\cline { 2 - 5 } & \multicolumn{1}{|c|}{$\boldsymbol{B}$} & \multicolumn{1}{c|}{$\boldsymbol{C}$} & $\boldsymbol{D}$ \\
\hline AR & $\mathbf{2 1 8 . 1}$ & 399.9 & 411.9 & 446.1 \\
\hline RB & 865.8 & 828.2 & 869.3 & 849.3 \\
\hline RT & 341.4 & 351.4 & 396.4 & 388.3 \\
\hline RKh & 465.2 & 419.2 & 465.0 & $\mathbf{2 7 5 . 0}$ \\
\hline AK & 588.7 & 651.1 & 653.9 & 525.0 \\
\hline ZK & 600.5 & 556.1 & 602.7 & 587.7 \\
\hline KO & 1861.4 & 1817.9 & 1857.3 & $\mathbf{1 1 3 . 9}$ \\
\hline IO & 796.7 & 753.5 & 792.3 & $\mathbf{3 9 6 . 5}$ \\
\hline KO & 765.9 & 730.4 & $\mathbf{3 3 0 . 7}$ & 665.8 \\
\hline NO & 512.5 & 470.7 & 503.3 & 386.5 \\
\hline OO & 1961.9 & 1922.8 & 1929.7 & $\mathbf{1 5 7 . 6}$ \\
\hline TO & 1149.6 & 1111.0 & $\mathbf{2 7 2 . 6}$ & 1067.8 \\
\hline
\end{tabular}

TABLE VIII. VALUES OF $I_{K}$ FOR SUBJECTS BY OKVED SECTIONS IN 2014 (PART 2)

\begin{tabular}{|l|l|l|l|l|}
\hline \multirow{2}{*}{ Subjects } & \multicolumn{4}{|c|}{ OKVED Sections E-D } \\
\cline { 2 - 5 } & \multicolumn{1}{|c|}{$\boldsymbol{F}$} & \multicolumn{1}{c|}{$\boldsymbol{G}$} & $\boldsymbol{H}$ \\
\hline AR & 432.4 & 447.2 & 428.4 & 413.1 \\
\hline RB & 873.4 & 865.5 & 813.5 & 837.5 \\
\hline RT & 388.3 & 395.7 & 351.9 & 358.3 \\
\hline RKh & 448.0 & 456.2 & 419.7 & 424.7 \\
\hline AK & 697.7 & 694.5 & $\mathbf{4 5 3 . 3}$ & 661.8 \\
\hline ZK & 602.0 & 603.2 & 532.8 & 569.3 \\
\hline KO & 1860.5 & 1862.2 & 1863.0 & 1828.6 \\
\hline IO & 798.1 & 794.0 & 755.4 & 765.5 \\
\hline KO & 777.8 & 776.0 & 723.5 & 743.6 \\
\hline NO & 509.9 & 505.5 & 462.4 & 481.3 \\
\hline OO & 1955.3 & 1966.7 & 1952.1 & 1933.6 \\
\hline TO & 1140.4 & 1149.0 & 1147.4 & 1119.1 \\
\hline
\end{tabular}


TABLE IX. VALUES OF $I_{K}$ FOR SUBJECTS BY OKVED SECTIONS IN 2014 (PART 3)

\begin{tabular}{|l|l|l|l|l|}
\hline \multirow{2}{*}{ Subjects } & \multicolumn{4}{|c|}{ OKVED Sections I-L } \\
\cline { 2 - 5 } & \multicolumn{1}{|c|}{$\boldsymbol{I}$} & \multicolumn{1}{c|}{$\boldsymbol{J}$} & \multicolumn{1}{c|}{$\boldsymbol{L}$} & \multicolumn{1}{c|}{} \\
\hline AR & 445.6 & 447.2 & 443.4 & 411.1 \\
\hline RB & $\mathbf{2 3 4 . 7}$ & 826.7 & 861.5 & 866.7 \\
\hline RT & 398.3 & 351.4 & 399.0 & 367.4 \\
\hline RKh & 419.7 & 417.8 & 454.0 & 463.1 \\
\hline AK & 697.9 & 652.5 & 697.2 & 695.7 \\
\hline ZK & $\mathbf{2 1 1 . 4}$ & 556.1 & 603.6 & 603.5 \\
\hline KO & 1849.8 & 1819.3 & 1862.2 & 1851.1 \\
\hline IO & 604.9 & 754.9 & 796.1 & 791.7 \\
\hline KO & 770.0 & 736.0 & 777.4 & 762.0 \\
\hline NO & 393.5 & 482.5 & 468.3 & 508.7 \\
\hline OO & 1969.3 & 1924.3 & 1967.8 & 1953.6 \\
\hline TO & 1146.0 & 1109.6 & 1155.8 & 1142.0 \\
\hline
\end{tabular}

TABLE $X . \quad$ VALUES OF $I_{K}$ FOR SUBJECTS BY OKVED SECTIONS IN 2014 $\left(\right.$ PART 4) ${ }^{\mathrm{A}}$

\begin{tabular}{|l|l|l|l|}
\hline \multirow{2}{*}{ Subjects } & \multicolumn{3}{|c|}{ OKVED Sections M-O } \\
\cline { 2 - 4 } & \multicolumn{1}{|c|}{$\boldsymbol{M}$} & \multicolumn{1}{c|}{$\boldsymbol{N}$} \\
\hline AR & 425.5 & 442.7 & 421.1 \\
\hline RB & 871.4 & 872.6 & 842.3 \\
\hline RT & 346.0 & 350.5 & 373.7 \\
\hline RKh & 460.9 & 462.1 & 432.2 \\
\hline AK & 696.4 & 698.2 & 667.8 \\
\hline ZK & 603.2 & 603.7 & 572.8 \\
\hline KO & 1851.9 & 1852.6 & 1832.3 \\
\hline IO & 795.1 & 794.6 & 769.1 \\
\hline KO & 763.6 & 769.2 & 744.8 \\
\hline NO & 511.9 & 516.9 & 486.1 \\
\hline OO & 1957.6 & 1956.0 & 1937.3 \\
\hline TO & 1146.5 & 1141.2 & 1120.3 \\
\hline
\end{tabular}

${ }^{\text {a }}$ Source: Authors' calculations

The advantage of this approach consists in the fact that it makes it possible to reveal deviations of data in analyzed rows. For example, the line for Krasnoyarsk Kray contains a value that is more prominent in column D. The phenomenon means that, when determining the sum of squared deviations without regard to Section $D$, the value appears to be significantly lower (viz. 113.9) whereas, when calculating for other sections with Section D involved, the value of index becomes higher almost everywhere (viz. more than 1800). This relative identity reveals insignificance of fluctuations of the shares of these sections with regard to the overall GRP structure of the subject of the Russian Federation in comparison to the section that shows significant deviation from this level. A similar situation with Section D is registered in the Republic of Khakassia, Irkutsk Oblast, and Omsk Oblast. Other subjects have their prominent sections as well. Distinguishing the indicator on Section $\mathrm{C}$ for Kemerovo Oblast and Tomsk Oblast is also rightly.

Further practical application of the presented approach requires determination of a general integrated indicator characterizing the entire GRP structure of a subject of the Russian Federation. Therefore, we calculated the sum of the squared deviations for the obtained data rows $I_{k}(4)$ in order to determine the overall structure index ${ }^{7}$.

${ }^{7}$ Reduction to 10000 has no significant importance and is done for better perception of the obtained results.

$$
I_{s}=\frac{\sum\left(I_{k}-\bar{I}\right)^{2}}{10000}
$$

The lower the value of the integrated structure index structure for a particular subject of the Russian Federation is, the less deformation of the economic structure it will suffer provided that other conditions are equal. Tab. 11, 12 show results of the calculation of this index.

TABLE XI. VALUES OF THE STRUCTURE INDEX $\left(I_{S}\right)$ FOR SUBJECTS IN 2005-2014 (PART 1)

\begin{tabular}{|l|l|l|l|l|l|l|}
\hline \multirow{2}{*}{ Year } & \multicolumn{7}{|c|}{ Subjects } \\
\cline { 2 - 7 } & $\boldsymbol{A R}$ & $\boldsymbol{R} \boldsymbol{R}$ & $\boldsymbol{R} \boldsymbol{A}$ & $\boldsymbol{R} \boldsymbol{h}$ & $\boldsymbol{A} \boldsymbol{Z}$ & $\boldsymbol{Z}$ \\
\hline 2005 & 4.5 & 36.2 & 0.7 & 3.2 & 7.4 & 13.8 \\
\hline 2006 & 4.9 & 22.6 & 0.7 & 2.8 & 5.7 & 10.5 \\
\hline 2007 & 4.0 & 26.8 & 3.6 & 3.9 & 9.1 & 8.6 \\
\hline 2008 & 3.1 & 24.4 & 6.0 & 1.6 & 5.6 & 8.2 \\
\hline 2009 & 4.0 & 8.8 & 7.9 & 1.2 & 4.3 & 9.3 \\
\hline 2010 & 4.5 & 6.2 & 5.0 & 1.0 & 6.0 & 6.2 \\
\hline 2011 & 4.7 & 3.0 & 5.6 & 0.7 & 4.1 & 9.3 \\
\hline 2012 & 4.8 & 2.3 & 8.3 & 0.8 & 3.4 & 7.3 \\
\hline 2013 & 3.1 & 1.2 & 9.5 & 0.6 & 3.1 & 8.0 \\
\hline 2014 & 1.9 & 1.9 & 8.0 & 0.7 & 2.4 & 7.2 \\
\hline
\end{tabular}

TABLE XII. VALUES OF THE STRUCTURE INDEX $\left(I_{S}\right)$ FOR SUBJECTS IN 2005-2014 (PART 2)

\begin{tabular}{|l|l|l|l|l|l|l|}
\hline \multirow{2}{*}{ Year } & \multicolumn{7}{|c|}{ Subjects } \\
\cline { 2 - 7 } & $\boldsymbol{K O}$ & \multicolumn{1}{|}{$\boldsymbol{O} \boldsymbol{O}$} & \multicolumn{1}{|c|}{$\boldsymbol{O}$} & $\boldsymbol{O O}$ & $\boldsymbol{T O}$ \\
\hline 2005 & 281.0 & 16.2 & 17.6 & 2.3 & 299.9 & 69.6 \\
\hline 2006 & 461.8 & 20.6 & 6.6 & 2.2 & 137.3 & 20.2 \\
\hline 2007 & 378.6 & 5.8 & 11.4 & 2.5 & 103.4 & 11.1 \\
\hline 2008 & 95.4 & 4.1 & 24.0 & 2.4 & 111.8 & 18.5 \\
\hline 2009 & 61.4 & 5.0 & 12.1 & 1.4 & 75.2 & 5.4 \\
\hline 2010 & 62.0 & 6.8 & 38.0 & 2.6 & 64.4 & 8.5 \\
\hline 2011 & 60.0 & 2.2 & 62.4 & 3.0 & 92.1 & 30.5 \\
\hline 2012 & 29.1 & 1.7 & 16.6 & 2.9 & 97.3 & 37.5 \\
\hline 2013 & 21.9 & 2.0 & 6.4 & 3.5 & 79.6 & 26.1 \\
\hline 2014 & 34.5 & 3.5 & 6.6 & 4.6 & 98.4 & 23.1 \\
\hline
\end{tabular}

The structure index shows fluctuation of shares in the GRP structure of subjects of the Siberian Federal District, which proves heterogeneity of the structures of regional economies. The most equalized GRP structure is that of the Republic of Khakassia because its values were the lowest over the entire period of analysis. The most unbalanced GRP structure in terms of the size of shares of GRP is the structure of Omsk Oblast. In fact, almost all the subjects (except for the Republic of Tyva and Novosibirsk Oblast) demonstrate a steady tendency towards equalization of the shares in the GRP structure.

\section{CONCLUSION}

Thus, we have arrived at the following results and conclusions:

1) The analysis of published results of studies on the economic structure of federal districts showed prevalence of the strategy for economic specialization of subjects of the Russian Federation that constitute districts. 
2) The analysis of the values of Ryabtsev and Szalai indices revealed that the structures of economies of the Republic of Khakassia and Kemerovo Oblast are most similar to the structure of economy of the Siberian Federal District.

3) A tendency towards reducing the prevalent share of processing industries and increasing mineral extraction is observed in the Siberian Federal District in the period of analysis. Simultaneously, the share of GRP sections related to the maintenance (service) and social components of economic activity are being increased.

4) The Siberian Federal District shows a very slow drift towards more balanced participation of subjects of the district in the generation of the total amount of GRP.

5) The values of the index of the ratio of the subject's economic structure to the economic structure of the district reveal a tendency towards approximation despite the fact that these subjects belong to different economic areas.

6) Harmonization of economic structure within a federal district, including targeted allocation of economic units, is expected only in the distant future.

7) The developed universal method for assessment of convergence of structures of regional economies based on the indicator "GRP structure" is suggested for testing on the example of other Russian macroregions.

\section{References}

[1] S.A. Ayvazyan, A.V. Kudrov, and M.Yu. Afanas'yev, "Metod klasterizatsii regionov RF s uchetom otraslevoy struktury VRP",
Prikladnaya ekonometrika-Applied Econometrics, vol. 41, no. 1, pp. 24-26, 2016.

[2] S.R. Henzel, R. Lehmann, and K. Wohlrabe, "Nowcasting regional GDP: The case of the Free State of Saxony", Rev. Econ., vol. 66, no. 1, pp. 71-98, 2015.

[3] K.A. Kholodilin, S. Kooths, and B. Siliverstovs, "A dynamic panel data approach to the forecasting of the GDP of German Länder", Spat. Econ. Anal., vol. 3, no. 2, pp. 195-207, 2008.

[4] A. Kopoin, K. Moran, and J.P. Paré, "Forecasting regional GDP with factor models: How useful are national and international data?", Econ. Lett., vol. 121, no. 2, pp. 267-270, 2013.

[5] R. Lehmann and K. Wohlrabe, "Forecasting gross value-added at the regional level: Are sectoral disaggregated predictions superior to direct ones?", Rev. Regional Res., vol. 34, no. 1, pp. 61-90, 2014.

[6] S. Longhi and P. Nijkamp, "Forecasting regional labor market developments under spatial autocorrelation", Int. Regional Sci. Rev., vol. 30, no. 2, pp. 100-119, 2007.

[7] R. Patuelli, S. Longhi, P. Nijkamp, A. Reggiani, and U. Blien, "A rankorder test on the statistical performance of neural network models for regional labor market forecasts", Rev. Regional Stud., vol. 37, no. 1, pp. 64-81, 2007.

[8] N. Schanne, R. Wappler, and A. Weyh, "Regional unemployment forecasts with spatial interdependencies", Int. J. Forecasting, vol. 26, no. 4, pp. 908-926, 2010.

[9] E. Girardin and K.A. Kholodilin, "How helpful are spatial effects in forecasting the growth of Chinese provinces?", J Forecasting, vol. 30, no. 7, pp. 622-643, 2011.

[10] B.H. Baltagi, B. Fingleton, and A. Pirotte, "Estimating and forecasting with a dynamic spatial panel data model", Oxford B. Econ. Stat., vol. 76, no. 1, pp. 112-138, 2014.

[11] S. Longhi, P. Nijkamp, A. Reggiani, and E. Maierhofer, "Neural network modeling as a tool for forecasting regional employment patterns", Int. Regional Sci. Rev., vol. 28, no. 3, pp. 330-346, 2005.

[12] J. Stewart, "Assessing alternative dissimilarity indexes for comparing activity profiles”, Int. J. Time Use Res., vol. 3, no. 1, pp. 49-59, 2006. 